\title{
Medical uses for silver nitrate in the urinary tract (Review)
}

\author{
TAKANORI SEKITO $^{1}$, TAKUYA SADAHIRA ${ }^{1}$, TOYOHIKO WATANABE ${ }^{1}$, YUKI MARUYAMA ${ }^{1}$, \\ TOMOFUMI WATANABE ${ }^{1}$, TAKEHIRO IWATA ${ }^{1}$, KOICHIRO WADA ${ }^{2}$, \\ KOHEI EDAMURA ${ }^{1}$, MOTOO ARAKI $^{1}$ and MASAMI WATANABE ${ }^{3}$ \\ ${ }^{1}$ Department of Urology, Okayama University Graduate School of Medicine, Dentistry and Pharmaceutical Sciences, \\ Okayama 700-8558; ${ }^{2}$ Department of Urology, Shimane University School of Medicine, Izumo, Shimane 693-0021; \\ ${ }^{3}$ Center for Innovative Clinical Medicine, Okayama University Hospital, Okayama 700-8558, Japan
}

Received December 21, 2021; Accepted January 20, 2022

DOI: $10.3892 /$ wasj.2022.141

\begin{abstract}
Silver nitrate has been used for centuries for the treatment of a variety of diseases and in the prevention of infection. Silver nitrate exerts astringent, cauterizing and corrosive effects, as well as antimicrobial activities. Silver nitrate injection therapy has a long history of use in urology. It is reportedly effective for hemorrhagic cystitis, interstitial cystitis, renal hematuria and chyluria. The present review article summarizes the medical applications of silver nitrate in urology. The published studies available on the medical uses of silver nitrate are essentially older and retrospective, involving smaller numbers of patients. In the absence of comparative studies with other treatments, it is thus impossible to determine the relative benefits of silver nitrate. However, the outcomes of silver nitrate therapy have been fairly well established. Silver nitrate therapy may prove to be a treatment option for patients who are poor candidates for invasive treatment. Further studies on the uses of silver nitrate however, are required, and improvements also need to be made in the injection technique to reduce the rate of complications.
\end{abstract}

\section{Contents}

1. Introduction

2. Medical uses for silver nitrate in the bladder

3. Medical uses for silver nitrate in the upper urinary tract

4. Conclusion and future perspectives

Correspondence to: Dr Takuya Sadahira, Department of Urology, Okayama University Graduate School of Medicine, Dentistry and Pharmaceutical Sciences, Okayama 700-8558, Japan

E-mail: t.sadahira@gmail.com

Key words: silver nitrate, urinary tract, urinary bladder, therapeutic

\section{Introduction}

The use of silver for the treatment or prevention of infection dates back to at least 4,000 B.C.E. (1). Silver nitrate was used topically throughout the 1,800 s to treat infected wounds and ulcers, and to prevent gonococcal ophthalmic infection in newborns. It was also ingested to treat stomach ulcers based on its astringent, cauterizing and corrosive action, as well as its antimicrobial activities (1-3). These mechanisms of action are caused by the binding of free silver ions to tissue proteins and triggering the redox reaction (4).

Due to its various effects, silver nitrate has been used in a wide range of fields $(1-3,5,6)$. However, to the best of our knowledge, to date, there are only a limited number of reviews on the medical applications of silver nitrate. Thus, the present review article summarizes the medical applications of silver nitrate in urology.

\section{Medical uses for silver nitrate in the bladder}

Hemorrhagic cystitis (HC). $\mathrm{HC}$ is a condition secondary to radiation therapy, chemotherapy, stem-cell transplant therapy and virus infection with adenovirus, polyomavirus or cytomegalovirus (7). Diffuse inflammation causes bleeding from the bladder mucosa (8). The management options for this condition comprise coagulation, embolization, fulguration, hyperbaric oxygen therapy and surgical treatment (9). However, some patients experience intractable $\mathrm{HC}$ that is difficult to manage, particularly when the condition develops following the use of cyclophosphamide chemotherapy in combination with radiation therapy. Following radiation therapy, constant intravesical irrigation with silver nitrate (in solutions $>0.02 \%$ ) may be an effective, minimally invasive option compared with conventional treatments $(10,11)$. Some chronic cystoscopic findings with irradiation cystitis include an ulcerated lesion with a central sloughing area and a granulomatous edge. In such lesions, hemorrhage following biopsy can be controlled when the area is touched with a $20 \%$ solution of silver nitrate (10). Silver nitrate is less injurious to the bladder than other surgical procedures or cauterization with phenol or formalin (12).

In a previous study, Kumar et al (12) examined the efficacy of silver nitrate irrigations to control intractable hemorrhage 
from the bladder in 10 children with malignant diseases who had received cyclophosphamide therapy with or without irradiation. In total, 8 patients had received pelvic irradiation therapy. Bladder hemorrhage ceased within 24-48 h post-operatively in 9 patients following the instillation of $0.5-1 \%$ solutions of silver nitrate for $10-15$ min following the cystoscopic evacuation of clots and saline irrigation. The treatment was considered to have short-term effects, as 8 of the 10 patients had recurrent hematuria within 1 day or 2 years following treatment (12).

As previously demonstrated, a reported complication of irrigation of the bladder with a $1 \%$ solution of silver nitrate involved temporary anuria due to the obstruction of ureteral orifices caused by mucosal ulceration or edema, and the shedding of the bladder mucosa impregnated with silver salts (13). In another study, argyrosis of the urinary tract, or the diffuse deposition of silver, rarely occurred when the bladder was irrigated with a $0.01 \%$ solution of silver nitrate for $18 \mathrm{~h}$ following the instillation of a $10 \%$ silver nitrate solution for $5 \mathrm{~min}(14)$. The reflux and extravasation of silver nitrate from the upper urinary tract has also been observed in a patient with severe cyclophosphamide cystitis who received intravesical therapy with a $1 \%$ silver nitrate solution for $20 \mathrm{~min}$, resulting in secondary retroperitoneal inflammation (15). Not only the presence of silver nitrate in the upper tracts, but also the urothelium in the upper tracts affected by high-dose cyclophosphamide are considered predisposing factors for extravasation. Appropriate precautions prior to treatment can reduce complications when reflux is identified. Additionally, saline irrigation after silver nitrate instillation should be avoided to prevent the precipitation of silver chloride crystals (13).

Severe vesical bleeding in children is difficult to manage, as the small size of the urethra precludes the use of large catheters for bladder irrigation and clot removal. Thus, silver nitrate may prove to be particularly useful in pediatric patients (12). A previous study demonstrated that the intravesical administration of a $0.01-0.1 \%$ solution of silver nitrate was ineffective in 9 adult patients with refractory $\mathrm{HC}$ and that silver nitrate may have a limited role in the management of $\mathrm{HC}$; however, since the number of patients with $\mathrm{HC}$ treated with silver nitrate is limited, further investigations are required to determine the usefulness of this therapy (16).

Interstitial cystitis. Interstitial cystitis is considered a disease of unknown etiology, and the main symptoms include bladder pain, and urinary frequency and urgency (17). In particular, it may be associated with recurrent, severe bladder pain in the presence of Hunner's ulcers. In patients with interstitial cystitis, impairment of the glycosaminoglycan layer of the bladder mucosa occurs, and urine stimulates sensory nerves, such as unmyelinated C-fibers, which causes pain. Various treatments have been advocated and include local therapy with silver nitrate instillation in the bladder (18).

In 1944, Pool and Rives (19) used intravesical silver nitrate instillations in 74 patients, beginning from a dilute solution of $0.02 \%$ to a maximum concentration of $1 \%$. Symptoms including pain and urinary frequency improved in $89 \%$ of patients. The average duration of response was 7.6 months (range, 1 to 21 months). In 70 of 74 patients, follow-up data from $3.5-21$ months revealed no recurrence in $41 \%$ of patients (19).
The investigators recommended intravesical irrigation with increasing concentrations of silver nitrate following overdistention of the bladder as a greatly effective treatment (20).

Burford and Burford (21) demonstrated an improvement in $93 \%$ of patients $(n=187)$ with interstitial cystitis following silver nitrate instillation in combination with bladder fulguration. Symptoms included dysuria and nocturia caused by small bladder capacity and irritability. Bladder capacity, urinary frequency and nocturia were judged to evaluate the degree of improvement after each treatment. After $15 \mathrm{ml}$ of $5 \%$ cocaine hydrochloride was instilled into the bladder, $2 \%$ silver nitrate was instilled into the posterior urethra and vesical neck, and subsequently $30 \mathrm{ml}$ of $0.1 \%$ silver nitrate and $90-120 \mathrm{ml}$ water were added. After this liquid mixture was held in the bladder for $2 \mathrm{~min}$, it was flushed out with sterile water (21).

DeJuana and Everett (22) evaluated treatment with a $0.05 \%$ silver nitrate solution in 110 patients; $50 \%$ of all patients had a satisfactory result. The main symptoms included urinary frequency, nocturia and suprapubic pain, and half of the patients experienced a relief in these symptoms for at least 1 year. In addition, the combined treatment of overdistention with silver nitrate and superficial electrofulguration of the ulcers was more effective than silver nitrate instillation alone. However, silver nitrate can have adverse effects and potential complications can be caused by its potentially harmful effects on organs and tissues. Pelvic pain can occur following the intravesical silver nitrate instillation, and anesthesia may be required to control severe pelvic pain. Bladder biopsy should not be performed along with silver nitrate instillation to prevent perivesical extravasation. Advances in silver nitrate instillation techniques are required. One of the authors of the current review previously developed a novel, in situ permeation system that enables control of the intratissue diffusion of therapeutic agents and may be applicable to the localized ablation of target lesions (23).

\section{Medical uses for silver nitrate in the upper urinary tract}

Renal hematuria. Silver nitrate instillation has been used in the treatment of renal hematuria. The initial description of silver nitrate therapy was reported initially in 1950 by Goodwin et al (24), who treated a patient with renal hematuria by the open irrigation of the renal pelvis with $0.5 \%$ silver nitrate. Another study in 1952 demonstrated retrograde lavage with $0.2 \%$ silver nitrate $(25)$.

In the 1980s, the successful treatment of renal hematuria with silver nitrate instillation was reported for a small number of individuals $(26,27)$. Diamond et al (26) reported 4 patients with prolonged benign renal hematuria treated with silver nitrate instillation. They used $0.25-1.0 \%$ silver nitrate with a variable total volume $(3-26 \mathrm{ml})$ and periods of administration ranging from 1-3 days. The hematuria resolved within 4 days in each patient, although 1 patient reported transient flank pain and nausea with $1 \mathrm{ml}$ of $1 \%$ silver nitrate. They concluded that silver nitrate instillation may be an effective, safe treatment for renal hematuria, without requiring extirpative surgery (26). Bahnson (27) demonstrated the effective, successful resolution of significant renal hematuria in 3 patients with sickle cell hemoglobinopathy following pyelocaliceal irrigation with 
$10 \mathrm{ml}$ of a $1 \%$ silver nitrate solution. Although 2 of the 3 patients underwent an additional $1 \%$ instillation of silver nitrate on post-operative day 1 , no patient suffered from further hematuria for an average of 13 months (range, 11-15 months) (27).

Usually, a ureteral catheter is passed up to the renal pelvis at cystoscopy, and the retrograde instillation of silver nitrate is performed via the catheter. The catheter is left in place after instillation or clamped for 5-20 min just after instillation and then opened. If the hematuria remains, a second silver nitrate instillation can be performed (26-28). In a previous study, a Councill catheter was used to stabilize the ureteral catheter and to prevent its distal migration (27).

Ureteral stenosis following the retrograde intrapelvic instillation of silver nitrate has been reported as a severe complication (28). The progressive narrowing and rigidity of the ureter with hydronephrosis was detected after a $2.5 \%$ silver nitrate injection via a ureteral stent, which was considered an excessively caustic concentration. Preferably, a $\leq 1 \%$ silver nitrate solution should be used for the safe treatment of renal hematuria. Of note, no other severe consequences or systemic side-effects have been reported due to silver nitrate injection $(26,27)$, at least to the best of our knowledge. In addition, when silver nitrate is instilled into the renal pelvis as a chemical cauterization for five continuous minutes, aspiration from the pelvis must be performed to prevent inflammation of the ureteral mucosa and precipitation of silver chloride crystals (29). Monitoring by urinalysis and retroperitoneal ultrasound is also crucial following silver nitrate instillation.

In canines, the use of sclerotherapy as a treatment for renal hematuria has also been explored. A previous study demonstrated that clinical signs and anemia were resolved for 10 months in a canine with bilateral renal hematuria following the instillation of $0.5 \%$ silver nitrate (30). In another study, sclerotherapy led to the complete cessation of macroscopic hematuria in 4 of 6 canines within a median of $6 \mathrm{~h}$ (range, post-surgery to 7 days). In these canines, the infusion of $0.5-0 \%$ silver nitrate into the renal pelvis in combination with $5 \%$ povidone iodine was performed (31).

Finally, to the best of our knowledge, only limited data have been reported to date for refractory hematuria in the upper urinary tract (32). Silver nitrate instillation into the renal pelvis has been a common method for the conservative management of chronic renal hematuria to control recurrent, prolonged bleeding. Recently, Araki et al (33) demonstrated that the instillation of silver nitrate into the renal pelvis prior to ureteroscopy became less frequent after flexible ureteroscopy appeared as a treatment for chronic unilateral hematuria. Flexible ureteroscopy is the diagnostic and therapeutic technique of choice to control renal hematuria (32).

Chyluria. Chyluria is caused by the rupture of lymphatics into the renal pelvis or calices. It is a common condition among Asian populations, and is particularly observed in India (34), Japan (35,36), Hong Kong (37) and Taiwan (38). Wood described an incidental disappearance of chyluria following retrograde pyelography in 1929, which was considered the original description of renal pelvic irrigation treatment $(36,39)$. Silver nitrate therapy for chyluria was first reported in 1925 (40), and silver nitrate has been a commonly used agent for renal sclerotherapy (41).
Renal pelvic instillation can cauterize and obstruct fistulas between the renal lymphatics and the renal pelvis or calices (36). Silver nitrate instillation causes chemical lymphangitis and edema of the renal lymphatic channels as an inflammatory reaction. Consequently, a blockage of fistulas can relieve chyluria immediately, and permanent remission can be obtained due to subsequent fibrosis as a healing process (42).

The treatment of chyluria using the instillation of silver nitrate into the renal pelvis is considered a safe, effective and minimally invasive procedure. A previous study demonstrated that $77 \%$ of 55 patients responded to instillation of $10 \mathrm{ml}$ of $0.5 \%$ silver nitrate to the renal pelvis, leading to complete remission of chyluria (38). The instillation of $1 \%$ silver nitrate into the renal pelvis for the treatment chyluria has been shown to be a relatively safe, effective procedure with a success rate of $82 \%$ in 62 patients (42). Another study demonstrated a success rate of $70 \%$ following the instillation of $1 \%$ silver nitrate in 54 patients (43). In a large Japanese study, 585 patients were treated with $0.1-\%$ silver nitrate instillation, and chyluria ceased in $61 \%$ of patients and improved in $16 \%$ of patients (39). In terms of concentration, $0.5-1.0 \%$ silver nitrate has been recommended for the safe and effective treatment of chyluria (44).

However, certain complications have been documented with the instillation of $1.0 \%$ silver nitrate. Su et al (45) reported a case of acute necrotizing ureteritis following the instillation of $10 \mathrm{ml}$ of $1 \%$ silver nitrate, although the urine became clear post-treatment. The authors of that study argued that the coexisting urinary tract infection due to the long-term chyluria may have caused this severe complication (45). Sabnis et al (42) reported a series of 62 patients with chyluria, and treatment included a course of $10 \mathrm{ml}$ instillations of $1 \%$ silver nitrate every half hour for $2 \mathrm{~h}$ (four doses). The patients received 1-3 courses of silver nitrate with an interval of 6 weeks between courses. As a result, the treatment success rate was $82 \%$. Flank pain, nausea, vomiting and occasionally, hematuria occurred in a number of patients, although all these symptoms subsided in 24-48 h. One side should be treated at a time, with 6 -week intervals between instillations in patients with bilateral chyluria. Importantly, patients with severe symptoms were more likely to respond well to treatment (42).

Silver nitrate instillation has been shown to be associated with other severe complications, such as interstitial nephritis, sepsis and pyelonephritis (46). Kulkarni et al (47) reported a case of renal and fulminant hepatic failure following silver nitrate instillation for the treatment of chyluria, although the exact quantity and concentration were unknown. Another study also reported anuria immediately following the simultaneous instillation of $5 \mathrm{ml}$ of $3 \%$ silver nitrate solution into the bilateral renal pelvis. Following hemodialysis, urine output and renal parameters improved, and chyluria disappeared (48). Acute renal failure with acute tubular necrosis and ureteric strictures have also been reported following simultaneous bilateral instillation of $3 \%$ silver nitrate (49). Solutions of a higher concentration, such as $3 \%$, may thus be associated with a higher risk of severe complications.

In terms of the numbers of instillations, a previous study demonstrated that nine and three instillations of $1 \%$ silver nitrate instillations were equally effective (96.5 vs. $96.7 \%$, respectively), with more side-effects in the group that received 


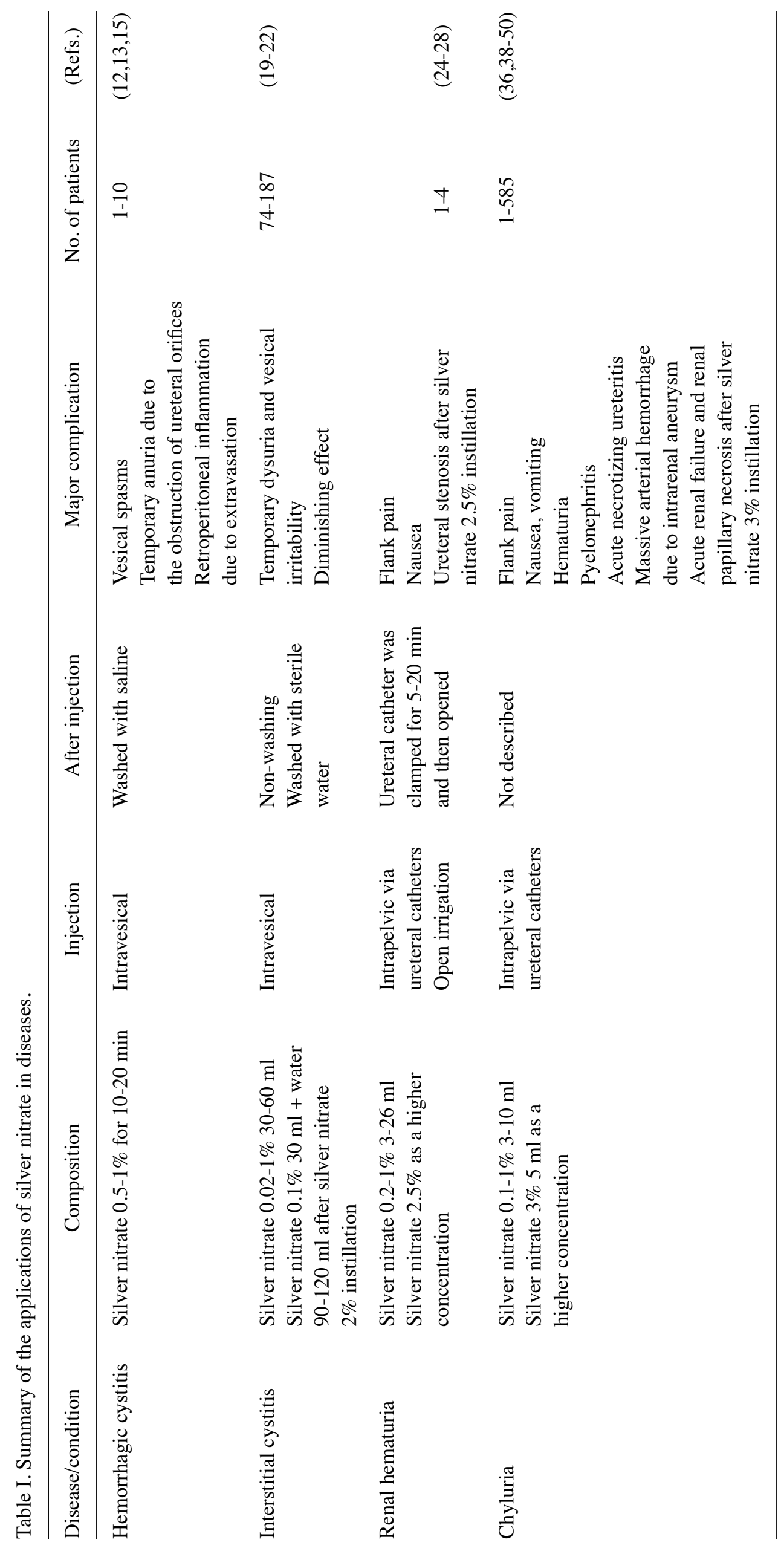


nine instillations (41). As previously demonstrated, a massive arterial hemorrhage caused by an intrarenal aneurysm occurred 8 years following multiple renal pelvis instillations with $1 \%$ silver nitrate for chyluria (50). Another study demonstrated that the rate of the spontaneous remission of chyluria was $50 \%$, and the duration of chyluria was within 6 months in half of the patients who experienced spontaneous remission (51). Thus, if the general condition of patients with chyluria is good, observation can also be considered. When the chyluria is refractory to conservative treatments, three instillations of silver nitrate should thus be performed, based on an associated shorter hospital stay and lesser cost.

\section{Conclusion and future perspectives}

In the field of urology, intravesical injection therapy is conventionally used in the treatment of patients by injecting various liquid drugs (e.g., silver nitrate, dimethyl sulfoxide, lidocaine, phenol and steroids) into the bladder to reach the entire surface tissue of the bladder (52-54). The therapeutic application of silver nitrate is reportedly effective for a wide variety of urological diseases (Table I). However, reports describing this therapy are primarily older and rely on small cohorts of patients. Silver nitrate instillation is not listed in treatment guidelines due to the advent of other therapeutic agents. In additions, the use of silver nitrate requires caution regarding environmental pollution. By changing the method of administration (e.g., local ablation), it is considered that silver nitrate can be used safely and may be re-evaluated for the treatment of refractory urinary tract diseases. Medical technologies are advancing daily, and technologies, such as robotic surgery and laser therapy are now available. The interest in minimally invasive treatment is increasing, and silver nitrate offers the advantages of avoiding unnecessary hospitalization and surgery. However, for silver nitrate to be used more effectively with fewer complications, it is necessary to improve the therapeutic techniques. In the future, silver nitrate may play a role in the treatment of urinary tract diseases as an active medical agent.

\section{Acknowledgements}

Not applicable.

\section{Funding}

No funding was received.

\section{Availability of data and materials}

Not applicable.

\section{Authors' contributions}

TSe and TSa wrote the manuscript. TSa, ToyW, YM and MW made substantial contributions to the conception and design of the present study and were involved in the literature search. TomW, TI, KW, KE and MA made substantial contributions to and were involved in the literature search and study selection for the review. TSa, ToyW, YM and MW made substantial contributions to the conception and design of the study, provided critical points of discussion and were involved in the completion of the manuscript. Data authentication is not applicable. All authors have read and approved the final manuscript.

\section{Ethics approval and consent to participate}

Not applicable.

\section{Patient consent for publication}

Not applicable.

\section{Competing interests}

The authors declare that they have no competing interests.

\section{References}

1. Alexander JW: History of the medical use of silver. Surg Infect (Larchmt) 10: 289-292, 2009.

2. Klasen HJ: Historical review of the use of silver in the treatment of burns. I. Early uses. Burns 26: 117-130, 2000.

3. Klasen HJ: A historical review of the use of silver in the treatment of burns. II. Renewed interest for silver. Burns 26: 131-138, 2000.

4. Dodgen DF: The United States Dispensatory. 27th edition. Osol A and Pratt R (eds). Lippincott, Philadelphia, PA, pp1039, 1973.

5. Soylu Özler G: Silver nitrate cauterization: A treatment option for aphthous stomatitis. J Craniomaxillofac Surg 42: e281-e283, 2014.

6. Womack JP, Kropa J and Jimenez Stabile M: Epistaxis: Outpatient management. Am Fam Physician 98: 240-245, 2018.

7. Riachy E, Krauel L, Rich BS, McEvoy MP, Honeyman JN, Boulad F, Wolden SL, Herr HW and La Quaglia MP: Risk factors and predictors of severity score and complications of pediatric hemorrhagic cystitis. J Urol 191: 186-192, 2014.

8. Manikandan R, Kumar S and Dorairajan LN: Hemorrhagic cystitis: A challenge to the urologist. Indian J Urol 26: 159-166, 2010.

9. Nabi G, Sheikh N, Greene D and Marsh R: Therapeutic transcatheter arterial embolization in the management of intractable haemorrhage from pelvic urological malignancies: Preliminary experience and long-term follow-up. BJU Int 92: 245-247, 2003.

10. Pool TL: Irradiation cystitis: Diagnosis and treatment. Surg Clin North Am 39: 947-951, 1959.

11. Goldstein AG, D'Escrivan JC and Allen SD: Haemorrhagic radiation cystitis. Br J Urol 40: 475-478, 1968.

12. Kumar AP, Wrenn EL Jr, Jayalakshmamma B, Conrad L, Quinn $\mathrm{P}$ and Cox C: Silver nitrate irrigation to control bladder hemorrhage in children receiving cancer therapy. J Urol 116: 85-86, 1976.

13. Raghavaiah NV and Soloway MS: Anuria following silver nitrate irrigation for intractable bladder hemorrhage. J Urol 118: 681-682, 1977.

14. Gordon DH, Singla SK, Goode R, Pollack HM and Glanz S: Argyrosis of the urinary tract. Am J Roentgenol 136: 423-426, 1981.

15. Jerkins GR, Noe HN and Hill DE: An unusual complication of silver nitrate treatment of hemorrhagic cystitis: Case report. J Urol 136: 456-458, 1986.

16. Montgomery BD, Boorjian SA, Ziegelmann MJ, Joyce DD and Linder BJ: Intravesical silver nitrate for refractory hemorrhagic cystitis. Turk J Urol 42: 197-201, 2016.

17. Akiyama Y, Luo Y, Hanno PM, Maeda D and Homma Y: Interstitial cystitis/bladder pain syndrome: The evolving landscape, animal models and future perspectives. Int J Urol 27: 491-503, 2020

18. Moldwin RM and Sant GR: Interstitial cystitis: A pathophysiology and treatment update. Clin Obstet Gynecol 45: 259-272, 2002.

19. Pool TL and Rives HF: Interstitial cystitis: Treatment with silver nitrate. J Urol 51: 520, 1944.

20. Pool TL: Interstitial cystitis: Clinical considerations and treatment. Clin Obstet Gynecol 10: 185-191, 1967. 
21. Burford EH and Burford CE: Hunner ulcer of the bladder: A report of 187 cases. J Urol 79: 952-955, 1958.

22. DeJuana CP and Everett JC Jr: Interstitial cystitis: Experience and review of recent literature. Urology 10: 325-329, 1977.

23. Watanabe M: A novel in situ permeation system and its utility in cancer tissue ablation. Int J Oncol 47: 875-883, 2015.

24. Goodwin WE, Alston EF and Semans JH: Hematuria and sickle cell disease; unexplained, gross unilateral, renal hematuria in Negroes, coincident with the blood sickling trait. J Urol 63: 79-96, 1950.

25. Harrison FG and Harrison FG Jr: Hematuria with sickle cell disease. J Urol 68: 943-949, 1952.

26. Diamond DA, Jeffs RD and Marshall FF: Control of prolonged, benign, renal hematuria by silver nitrate instillation. Urology 18 : 337-341, 1981.

27. Bahnson RR: Silver nitrate irrigation for hematuria from sickle cell hemoglobinopathy. J Urol 137: 1194-1195, 1987.

28. Vijan SR, Keating MA and Althausen AF: Ureteral stenosis after silver nitrate instillation in the treatment of essential hematuria. J Urol 139: 1015-1016, 1988.

29. Reddy PP: Pediatric ureteroscopy. Urol Clin North Am 31: 145-156, 2004

30. Di Cicco MF, Fetzer T, Secoura PL, Jermyn K, Hill T, Chaloub S and Vaden S: Management of bilateral idiopathic renal hematuria in a dog with silver nitrate. Can Vet J 54: 761-764, 2013.

31. Berent AC, Weisse CW, Branter E, Adams LG, Aarhus A, Smee N, Berg R and Bagley DH: Endoscopic-guided sclerotherapy for renal-sparing treatment of idiopathic renal hematuria in dogs: 6 Cases (2010-2012). J Am Vet Med Assoc 242: 1556-1563, 2013.

32. Tanimoto R, Kumon H and Bagley DH: Development of endoscopic diagnosis and treatment for chronic unilateral hematuria: 35 years experience. J Endourol 31 (Suppl 1): S76-S80, 2017.

33. Araki M, Uehara S, Sasaki K, Monden K, Tsugawa M, Watanabe T, Monga M, Nasu Y and Kumon H: Ureteroscopic management of chronic unilateral hematuria: A single-center experience over 22 years. PLoS One 7: e36729, 2012.

34. Karanjavala DK: Technique of clearance (or disconnection) of dilated lymphatics in the renal hilum and lower ureter and bladder in cases of intractable chyluria or haemochyluria. Brit J Urol 51: 440-442, 1979.

35. Yamauchi S: Chyluria: Clinical, laboratory and statistical study of 45 personal cases observed in Hawaii. J Urol 54: 318-347, 1945.

36. Okamoto K and Ohi Y: Recent distribution and treatment of filarial chyluria in Japan. J Urol 129: 64-67, 1983.

37. $\mathrm{Yu} \mathrm{HH}, \mathrm{Ngan} \mathrm{H}$ and Leong $\mathrm{CH}$ : Chyluria-a 10 year follow-up. $\mathrm{Br}$ J Urol 50: 126-133, 1978

38. Tan LB, Chiang CP, Huang $\mathrm{CH}$, Chou $\mathrm{YH}$ and Wang $\mathrm{CJ}$ : Experiences in the treatment of chyluria in Taiwan. J Urol 144: 710-713, 1990

39. Okamoto K, Asechi S and Nagai K: Distribution of chyluria and its treatment in Japan. Urol Int 17: 241-256, 1964.

40. Kutzmann AA: Non-parasitic chyluria. Ann Surg 82: 765-780, 1925.

41. Dhabalia JV, Pujari NR, Kumar V, Punia MS, Gokhale AD and Nelivigi G: Silver nitrate sclerotherapy for chyluria: Evaluation for the optimal instillation regime. Urol Int 85: 56-59, 2010.
42. Sabnis RB, Punekar SV, Desai RM, Bradoo AM and Bapat SD: Instillation of silver nitrate in the treatment of chyluria. Br J Urol 70: 660-662, 1992

43. Dalela D, Kumar A, Ahlawat R, Goel TC, Mishra VK and Chandra H: Routine radio-imaging in filarial chyluria-is it necessary in developing countries? Br J Urol 69: 291-293, 1992.

44. Dash SC, Bhargav Y, Saxena S, Agarwal SK, Tiwari SC and Dinda A: Acute renal failure and renal papillary necrosis following instillation of silver nitrate for treatment of chyluria. Nephrol Dial Transplant 11: 1841-1842, 1996.

45. Su CM, Lee YC, Wu WJ, Ke HL, Chou YH and Huang $\mathrm{CH}$ : Acute necrotizing ureteritis with obstructive uropathy following instillation of silver nitrate in chyluria: A case report. Kaohsiung J Med Sci 20: 512-515, 2004

46. Nandy PR, Dwivedi US, Vyas N, Prasad M, Dutta B and Singh PB: Povidone iodine and dextrose solution combination sclerotherapy in chyluria. Urology 64: 1107-1110, 2004.

47. Kulkarni AA, Pathak MS and Sirsat RA: Fatal renal and hepatic failure following silver nitrate instillation for treatment of chyluria. Nephrol Dial Transplant 20: 1276-1277, 2005.

48. Gulati MS, Sharma R, Kapoor A and Berry M: Pelvi-calyceal cast formation following silver nitrate treatment for chyluria. Australas Radiol 43: 102-103, 1999.

49. Mandhani A, Kapoor R, Gupta RK and Rao HS: Can silver nitrate instillation for the treatment of chyluria be fatal? $\mathrm{Br} \mathrm{J}$ Urol 82: 926-927, 1998.

50. Srivastava DN, Yadav S, Hemal AK and Berry M: Arterial haemorrhage following instillation of silver nitrate in chyluria: Treatment by coil embolization. Australas Radiol 42: 234-235, 1998.

51. Ohyama C, Saita H and Miyasato N: Spontaneous remission of chyluria. J Urol 121: 316-317, 1979.

52. Yoshimura N, Homma Y, Tomoe H, Otsuka A, Kitta T, Masumori N, Akiyama Y, Niimi A, Mitsui T, Nanri M, et al: Efficacy and safety of intravesical instillation of KRP-116D (50\% dimethyl sulfoxide solution) for interstitial cystitis/bladder pain syndrome in Japanese patients: A multicenter, randomized, double-blind, placebo-controlled, clinical study. Int J Urol 28: 545-553, 2021.

53. Sadahira T, Maruyama Y, Watanabe T, Sekito T, Mitsui Y, Wada K, Araki M and Watanabe M: Medical uses for phenol in the urinary tract: A possible forgotten treatment (Review). Med Int 1: 13, 2021

54. Funaro MG, King AN, Stern JNH, Moldwin RM and Bahlani S: Endoscopic injection of low dose triamcinolone: A simple, minimally invasive, and effective therapy for interstitial cystitis with Hunner lesions. Urology 118: 25-29, 2018

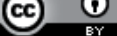

This work is licensed under a Creative Common Attribution 4.0 International (CC BY 4.0) License. 